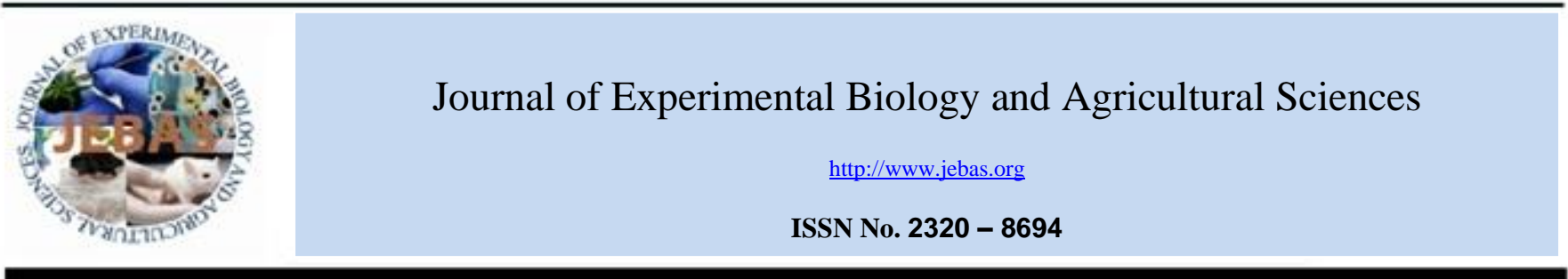

\title{
NEURODEGENERATIVE DISEASES: IMPACT OF PESTICIDES
}

\section{Neha Singh (iD, Priyanka Gautam}

Bioinformatics Lab, Department of Zoology, Dayalbagh Educational Institute, (Deemed University) Dayalbagh, Agra-282005, India

Received - July 01, 2021; Revision - September 21, 2021; Accepted - October 05, 2021

Available Online - October 30, 2021

DOI: http://dx.doi.org/10.18006/2021.9(5).572.579

\section{KEYWORDS}

Neurodegenerative Diseases

Environmental toxicants

Pesticides

Word Health Organization

Neurotransmitters

\begin{abstract}
Pesticides are widely used to fulfill the higher yield requirement for humans in agricultural practices and the repellents to kill the unwanted insects but excess uses of these pesticides combat various diseases and are also responsible for environmental pollution. Total 234 pesticides are registered in India out of these, four pesticides are WHO class 1a pesticide, 15 are WHO class $1 \mathrm{~b}$ pesticides, and 76 are WHO class 2nd mentioned pesticides together constituting $40 \%$ registered pesticides. Excess use of pesticides can cause fatigue, headache, respiratory problems, and neurodegenerative diseases in human beings. Neurodegenerative disease is the result of a process called neuron degeneration in which the structure and functions of the neurons are progressively degenerate. Alzheimer's, Parkinson's, Amyotrophic lateral sclerosis impose a burden on most of society. In the present study, we are emphasizing the mode of action of the various pesticides that influenced neurodegenerative diseases that is necessary to check the effect of neurotoxicants.
\end{abstract}

* Corresponding author

E-mail: drpriya18@gmail.com (Priyanka Gautam); nehasingh.kain@gmail.com (Neha Singh)

Peer review under responsibility of Journal of Experimental Biology and Agricultural Sciences.

Production and Hosting by Horizon Publisher India [HPI] (http://www.horizonpublisherindia.in/).

All rights reserved.
All the articles published by Journal of Experimental Biology and Agricultural Sciences are licensed under a Creative Commons Attribution-NonCommercial 4.0 International License Based on a work at www.jebas.org.

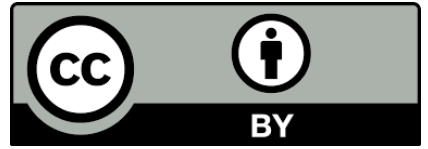




\section{Introduction}

Pesticides are defined as substances intended to kill the pests, insects and other biological organisms (National pesticide information center). The major classes of pesticides are insecticides, herbicides, fungicides, and nematicides (Aktar et al., 2009), which are used to control insects, herbs, fungus, and nematodes respectively. More than 500 non-biodegradable formulations of pesticides are used in agricultural practices that enhance environmental toxicity and synthetic pesticides are more dangerous to the environment and result in serious environmental and human health concerns (Harlow et al., 2020).

\subsection{Production and Contamination of Pesticides in India}

In 1952, India started the production of pesticides after china and rank, twelfth globally. India is the second-largest manufacturer of pesticides in Asia (Aktar et al., 2009). India used 76\% of insecticides used which is the highest in the world at $44 \%$. According to the "All India Coordinated Research Project Pesticide Residues (1999) (AICRPPR) report that food commodities were affected by pesticides. This report finds that $43.4 \%$ of a sample of milk exceeds DDT MRLs. In Uttar Pradesh and Kerala-like, more than $40 \%$ of samples of fruits and vegetables exceeded the MRLs (Maximum residue limits) (Bhushan et al., 2013). Pesticides affect people who spray the pesticides like agricultural workers as it is hazardous more at the time of manufacture and formulation (Aktar et al., 2009; Javaid et al., 2016).

\subsection{Ways of Pesticides Exposure in Human}

Air, soil, water, and food are different ways through which; humans get exposed to pesticides and are sensitive to the various adverse effects of pesticides (National Research Council U.S., 1993). When the pesticides are applied directly to the target pest, the whole site gets affected, including the crop plants, soil organisms, and humans. The pesticides use differently for exposure; in the air during spraying and vapors are come to contact with the human by their respiratory system (Boyd et al., 2012). Through soil, the route is hand-to-mouth behavior and dermal contact, while the children are exposed when the children are surrounding the spraying area. Another route of exposure is water and food, and fruits, vegetables, meat, dairy are the exposure sources (Pesticides, 2008). Pesticides are easy and inexpensive substances to control the weeds, pests, and insects to protect agricultural fields (WHO 1990; Aktar et al., 2009). Many repellents, sprayers, coils, are used to control the insects in the house and gardens. In this repellent, the companies used pesticides and aerosols that stay in the air and affect the human being with breathing and causes diseases (Rahman et al., 2001).

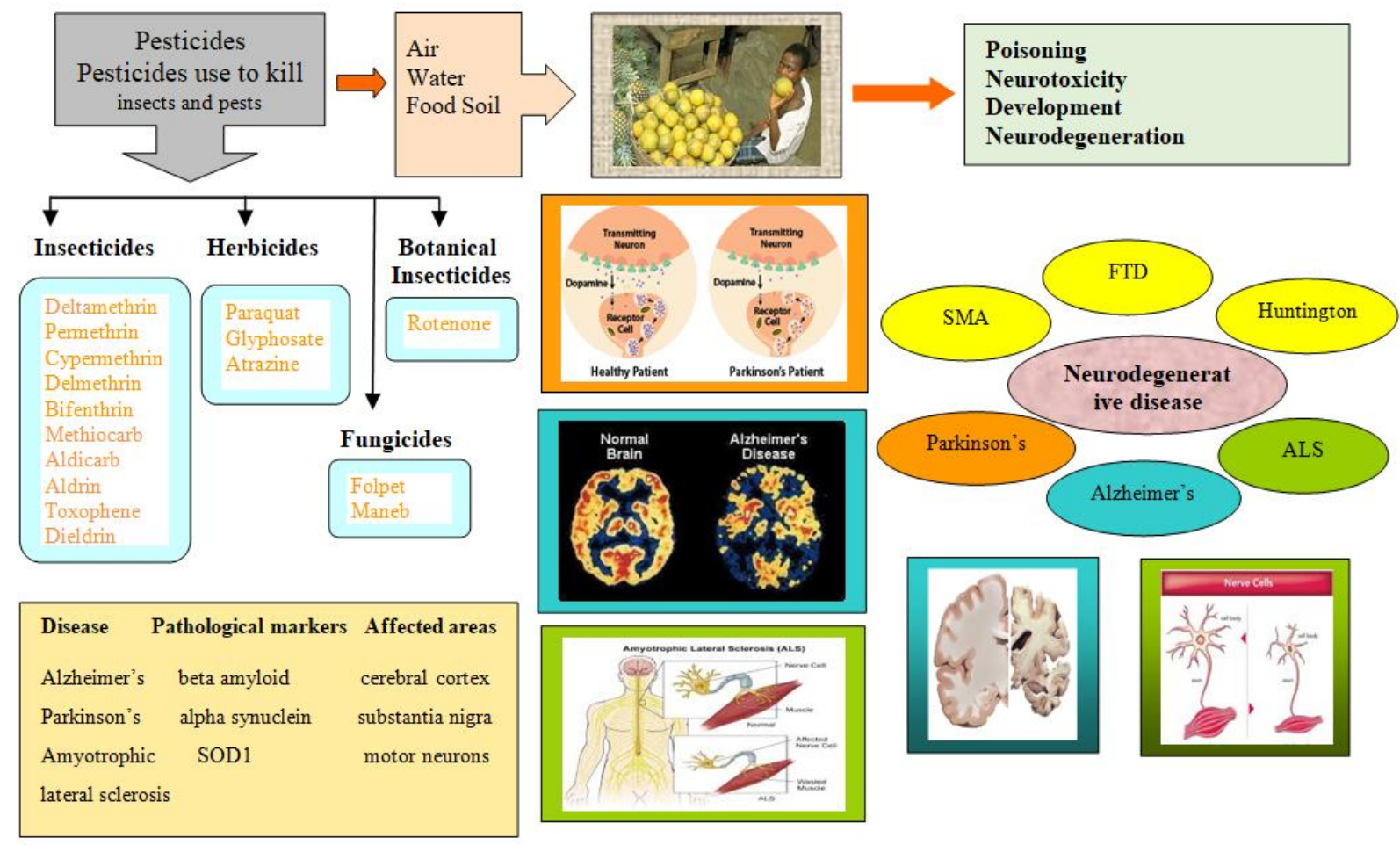

Figure 1 Representative diagram of pesticides exposure ways and the related diseases 
Table 1 Showing the list of various classes of pesticides that is commonly used in commercial as well as agricultural practices and have ability to cause neurodegenerative diseases

\begin{tabular}{|ccc|}
\hline Carbamate & Path of action & Neurodegenerative diseases \\
\hline Organophosphate & Inhibit Acetylcholinestrase & Alzheimer's disease (Fukuto, 1990) \\
\hline Pyrethroid & Dopamine Acetylcholinestrase & $\begin{array}{c}\text { Parkinson's disease and Alzheimer's } \\
\text { diseases (Yadav et al., 2016) }\end{array}$ \\
\hline Botanical insecticides & Dopamine & Parkinson's disease (Elwan et al., 2006) \\
\hline
\end{tabular}

\section{Pesticides Mode of Action}

In various modes of action, pesticides can come into the contact with humans and cause neurodegenerative diseases due to the over expression and mutation in the gene that directs the production of enzymes like aspartoacylase (ASPA) this allows the buildup of $\mathrm{N}$ acetyl aspartic acid (NAA) in the brain. This causes the damage of the myelin sheet that provides the protective coating to the nerve fiber in the brain that ensures that nerve impulses are properly transmitted in the brain (Palop \& Mucke, 2010). Loss of glutamate transporter EAAT2 (excitatory amino acid transporter 2) protein in the motor cortex and spinal cord, glutamate-mediated excitotoxicity of nitric oxide synthesis containing neurons results in the Paraquat induced neurotoxicity (Uversky, 2004). Pesticides may also be one of the reasons for the degeneration of the neurons as earlier studies show that the pesticides like Rotenone, Carbamates are the known pesticides that are causing neurodegenerative diseases like Huntington's and Alzheimer's respectively (Harms et al., 2021). As longevity increases, neurodegenerative diseases become more problematic, specifically when the treatments for these diseases are unavailable or ineffective.

\subsection{Alzheimer's Disease}

The mechanism of carbamates poisoning involves the inactivation of acetylcholinesterase which causes the loss of acetylcholine neurotransmitters. Carbamate causes the inhibition of acetylcholinesterase (AChE) enzyme important for transmission in nerve impulses (Alhewairini et al., 2016). Exposure of organophosphates affects the nervous system by the accumulation of acetylcholine which results in the inhibition of acetylcholinesterase therefore the use of organophosphates increases the risk to develop Alzheimer's disease in the exposed population (Yadav et al., 2016). Acetylcholine was first discovered in the 1920s as the first known neurotransmitter and the role of Acetylcholine found in the brain plays a role in learning and memory (Alexander et al., 2014). When acetylcholinesterase enzyme inhibited the cholinergic toxicity which, resulted in the continuous stimulation of cholinergic receptors throughout the central and peripheral nervous systems (The United States Environment Protection Agency, 2007). Alzheimer's is virtually based on targeting of amyloid precursor protein (APP), Presenilin 1 or Presenilin 2, and Tau/PTL - 1 gene (Palop \& Mucke, 2010).
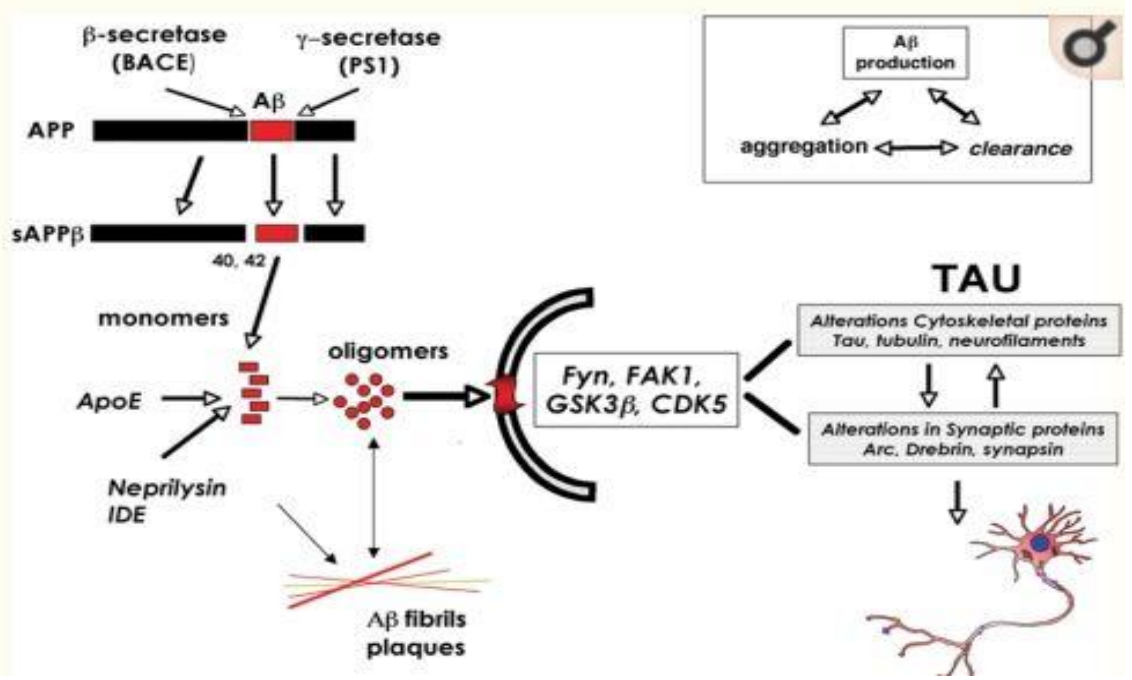

Figure 2 Mechanism of formation of beta amyloid plaques causes tau protein aggregation (Crews \& Masliah, 2010)

Journal of Experimental Biology and Agricultural Sciences

http://www.jebas.org 


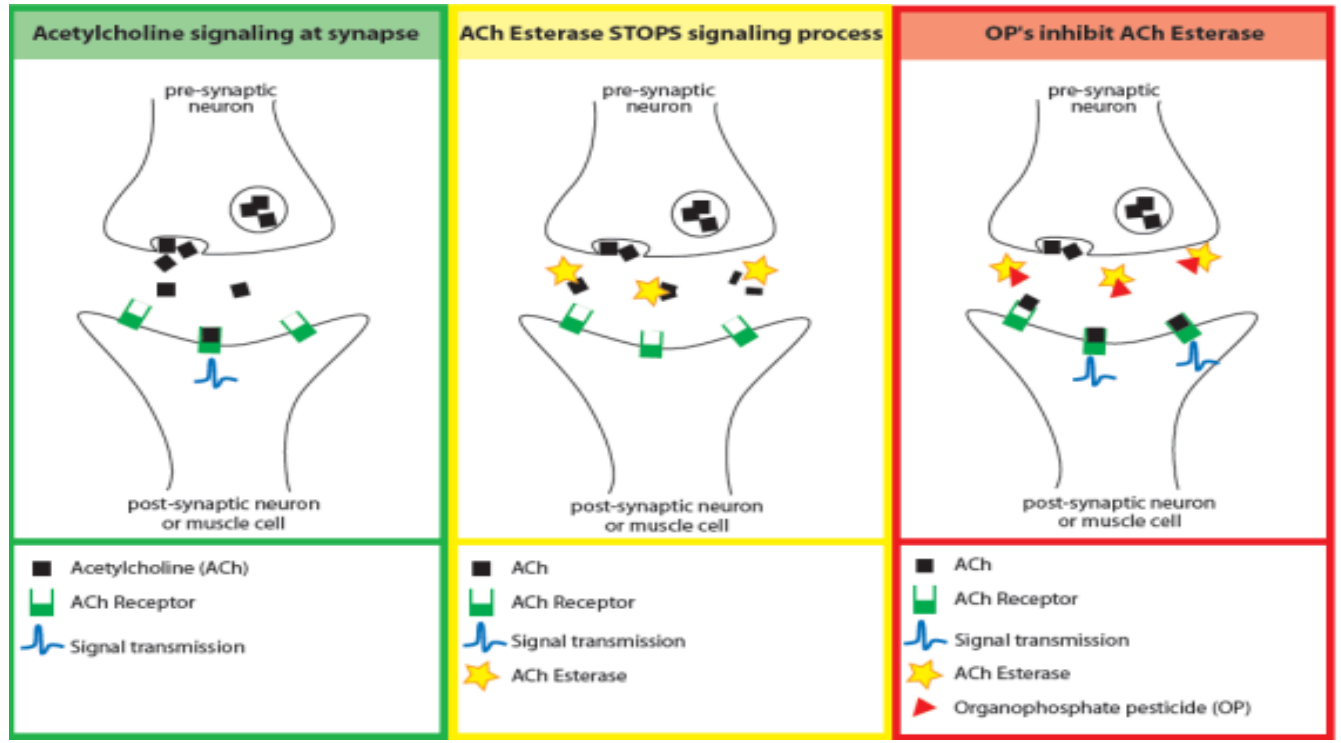

Figure 3 Mode of action of pesticide in the development of Alzheimer's disease (Organophosphate pesticides and child health, 2007)

\subsection{Parkinson's Disease}

The pyrethroids are also responsible to inhibit the dopaminergic neurons within the basal ganglia region of substantia nigra pars compacta that causes Parkinson's disease (Zhou et al., 2013). Dopaminergic neurons present during this region of the brain correlate with the motor cortex area that is liable for all the voluntary and involuntary movement within the body. Pyrethroids are utilized in many commercially available products that also are wont to control mosquitoes, professionals apply pyrethroids as an ultra-low volume (ULV) spray it releases very tiny aerosol droplets. These droplets stay within the air and kill the adult mosquitoes on contact. Parkinson's is that the second most common neurodegenerative disease including the selective

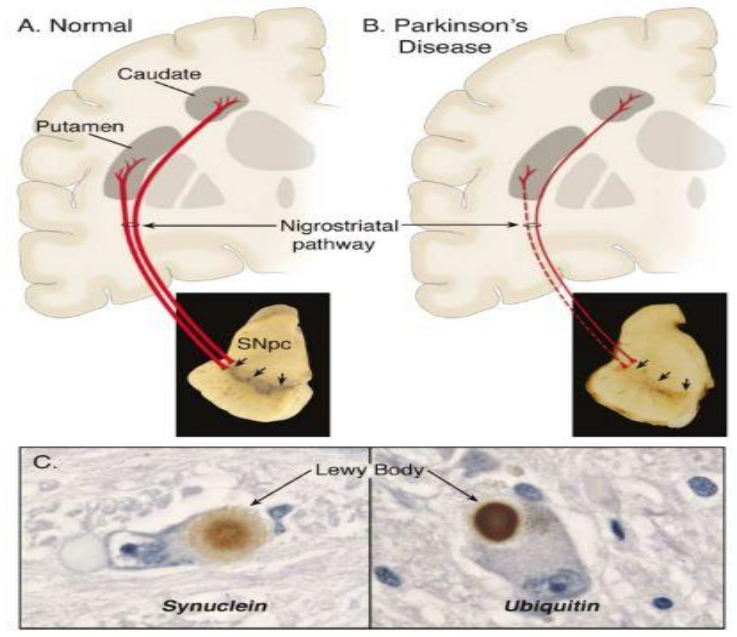

[a] neuronal degeneration by the nigrostriatal pathway through the protein accumulation of alpha-synuclein within the Lewy body inclusions (Cooper \& Raamsdonk, 2018). First described by James Parkinson in 1817 it's a disorder of the central nervous system that affects nerve cells within the part of the brain controlling muscle movement and impairs motor skills and speech (Nass et al., 2001). The symptoms of Parkinson's disease are tremor, rigidity, Bradykinesia (absence of movement), abnormalities, fatigue, soft speech, and learning disabilities. PARKIN, PINK 1, DJ-1, LRRK2 are the genes linked to Parkinson's disease which have an ortholog within the Caenorhabditis elegans model organism (Wolozin et al., 2011). C.elegans is used to predict chemical activity and identify mechanisms that can able to influence toxicological outcome (Harlow et al., 2020).

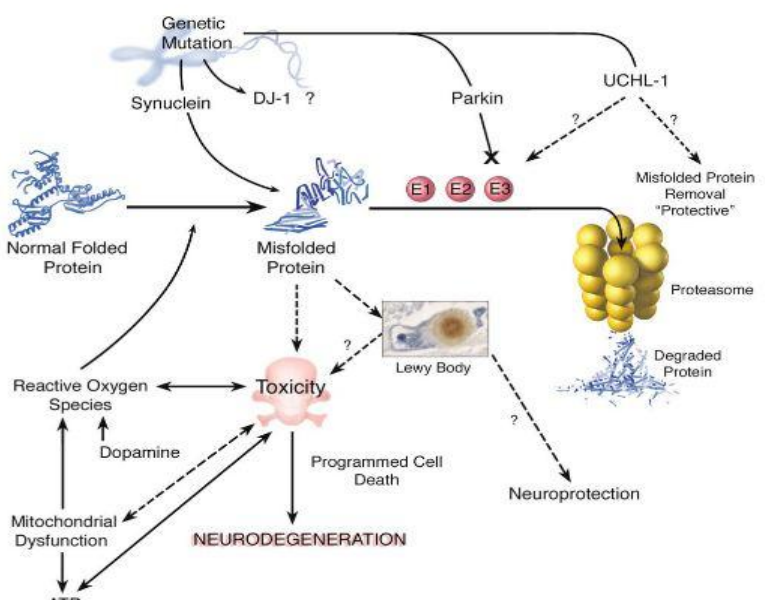

[b]

Figure 4 Parkinson's disease due to genetic mutation caused dopaminergic neurodegeneration (Dauer \& Przedborski, 2003)

Journal of Experimental Biology and Agricultural Sciences http://www.jebas.org 


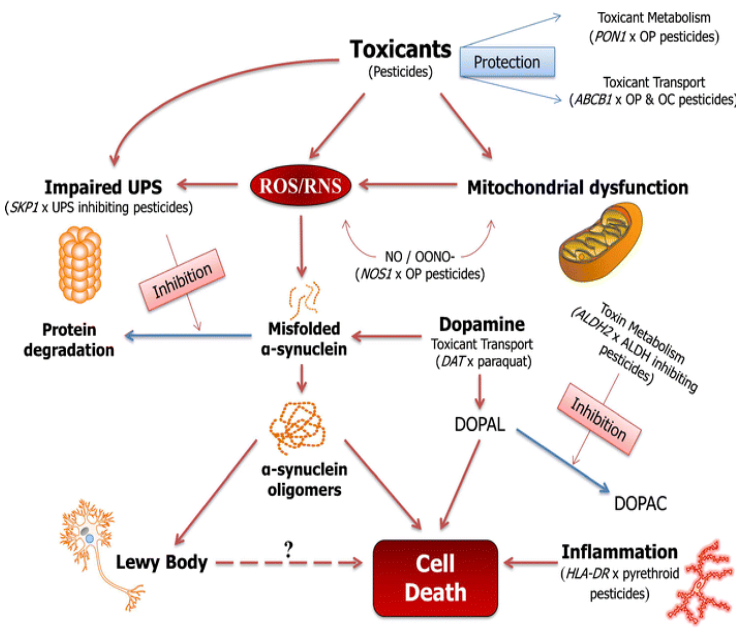

Figure 5 Mode of action of Parkinson's disease due to the effect of pesticides (Ritz et al., 2016)

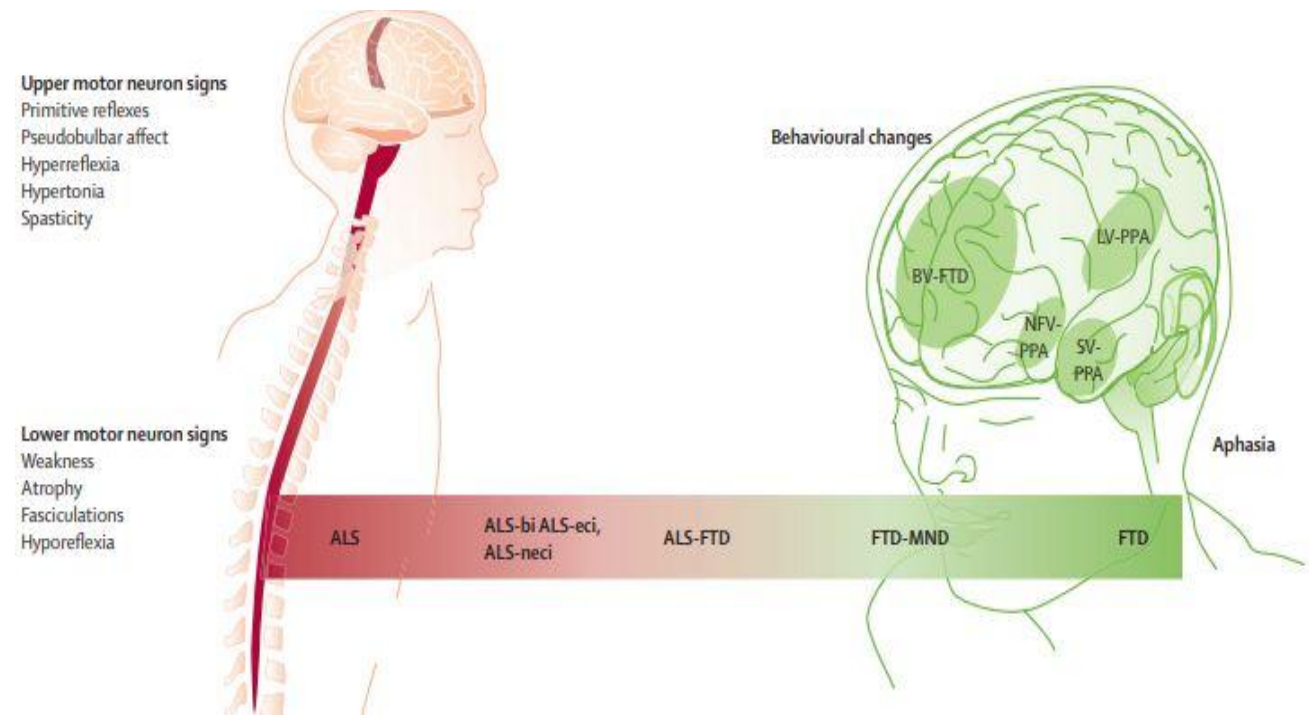

Figure 6 Representation of the upper and lower neurons identifiable for ALS (Michael et al., 2017)

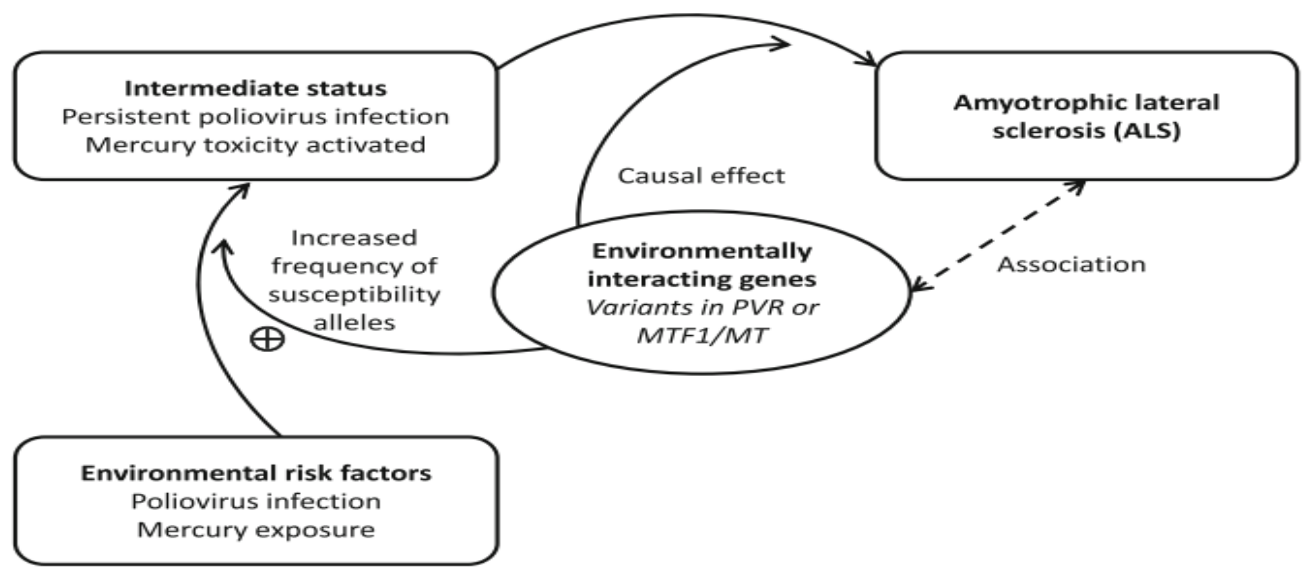

Figure 7 Mode of action of Amyotrophic lateral sclerosis due to the effect of pesticides (Yu \& Pamphlett, 2017)

Journal of Experimental Biology and Agricultural Sciences http://www.jebas.org 


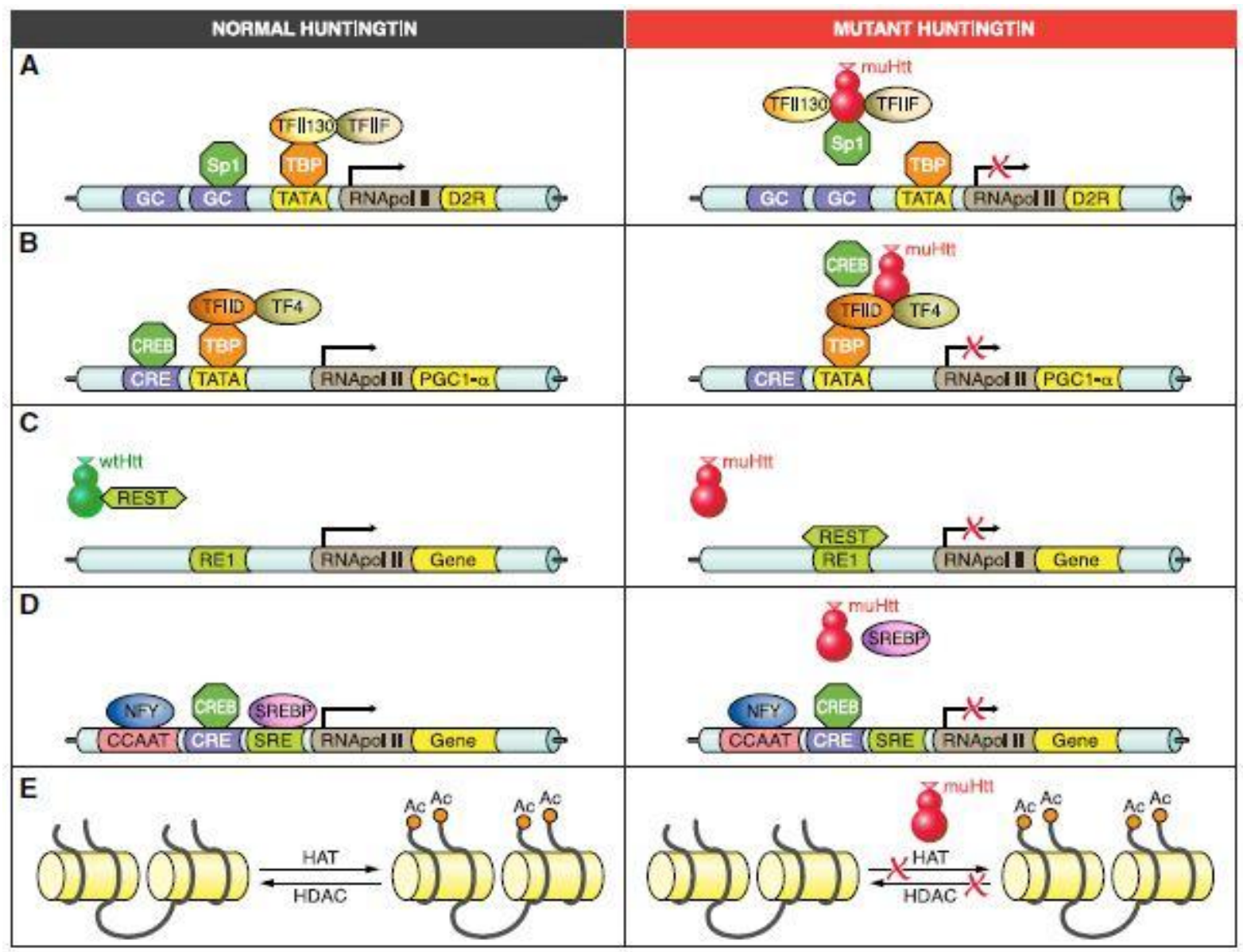

Figure 8 Molecular representation of normal and Huntington's disease pathway (Zuccato et al., 2010)

\subsection{Huntington's Disease}

Huntington's disease is additionally a neurodegenerative disease characterized by the degeneration of striatal GABAergic projection neurons but this do not affecting the striatal interneuron. It has been first introduced in 1872 and it's identified its mutated genes in 1993 (Zuccato et al., 2010). It's a dominant inherited neurodegenerative disorder caused due to the unstable expansion of a CAG repeat within the coding region of the IT- 15 gene which encodes for a protein called Huntingtin, and the mutation in this elongation of glutamine on the $\mathrm{NH} 2$ terminus of the protein (HD Collaborative Research Group, 1993).

\section{Conclusion}

Through the literature survey, was reported that there is a large number of pesticides such as Rotenone, Paraquat, Deltamethrin, Permethrin, and nicotine which belongs to herbicides, pyrethroids, and Botanical insecticides respectively. These pesticides classes can cause neuronal cell death and abnormalities in the motor cerebral cortex in the cerebellum and also in the basal forebrain region that denotes the neurodegenerative diseases i.e. Alzheimer's and Parkinson's. There have many diseases that are responsible to cause neurodegenerative diseases due to exposure of pesticides. Many researchers are currently working in the present area, to find out the pesticides having neurotoxic potential. The present study includes an overview of the work going on in the present area to explore the mechanism of neurotoxicity after exposure to pesticides. Therefore further work is required to check the activity of the various other pesticides that are used in agriculture as well as in household practices to control the pests.

\section{Author's Contribution}

NS is the first author who carried out the experiments, statistically analyzed and interpreted the data, and wrote the manuscript. PG was oversight responsibility for the research activity planning and acted as the corresponding author.

\section{Conflict of Interest}

The authors state that they have no conflict of interest. 


\section{References}

Aktar MW, Sengupta D, Chowdhury A (2009) Impact of pesticides use in agriculture: their benefits and hazards. Interdisciplinary Toxicology 2(1):1-12.

Alexander AG, Marfil V, Li C (2014) Use of Caenorhabditis elegans as a model to study Alzheimer's disease and other neurodegenerative diseases. Journal of Frontiers in Genetics 5: 279.

Alhewairini S, Mellor IR, Duce IR (2016) Caenorhabditis elegans as a test organism for detecting soil toxicity in Saudi Arabia. Journal of Environmental and Ecology Research 4:7-12.

Boyd WA, Smith MV, Freedman JH (2012) Caenorhabditis elegans as a model in developmental toxicology. Journal of Methods Molecular Biology 889:15-24.

Bhushan C, Avimuktesh Bhardwaj, Savvy Soumya Misra (2013) State of Pesticide Regulations in India, Centre for Science and Environment, New Delhi.

Cluskey S, Ramsden DB (2001) Mechanism of neurodegeneration in Amyotrophic Lateral Sclerosis. Molecular pathology 54 (6):386392.

Cooper JF, Raamsdonk JMV (2018). Modeling Parkinson's disease in C.elegans. Journal Parkinson's Disease 8: 17-32.

Crews L, Masliah E (2010) Molecular mechanisms of neurodegeneration in Alzheimer's disease. Human Molecular Genetics 19:12-20.

Dauer W, Przedborsk S (2003) Parkinson's disease: Mechanisms and Models. Neuron 39:889-909.

Elwan MA, Richordson JR, Guillot TS, Caudale WM, Miller GW (2006) Pyrethroid pesticides induced alterations in dopamine transporter function. Toxicology and Applied Pharmacology 211: 188-197.

Freire C, Koifman S (2012) Pesticide exposure and Parkinson's disease: Epidemiological evidence of association. Journal of Neurotoxicology 33: 947-971.

Fukuto TR (1990) Mechanism of action of organophosphate and carbamate pesticides. Environmental Health Perspectives 87: 245254.

Harlow PH, Perry SJ, Widdison S, Daniels S, Bondo E, Lamberth C, Flemming AJ (2020) The nematode Caenorhabditis elegans as a tool to predict chemical activity on mammalian development and identify mechanisms influencing toxicological outcome. Scientific reports 6: 2, 29-65.

Harms J, Wilson C, Everson R, Hooser S (2021) Organophosphate and Carbamate Insecticide Poisoning.

HD Collaborative Research Group (1993) A novel gene containing a trinucleotide repeat that is expanded and unstable on Huntington's disease chromosomes. Cell 72: 971-983.

Javaid MK, Ashiq M, Tahir M (2016) Biodegradation and environmental impacts of pesticides. Scientifica Pp. 1-9.

Lin DY, Fleming TR, Gruttola VDE (1998) Estimating the proportion of treatment effect explained by a surrogate marker. Statistics in Medicine 16(13):1515-27. doi: 10.1002/(sici)10970258(19970715)16:13<1515::aid-sim572>3.0.co;2-1.

Michael J, Cliff W, McFarland JL, Modell H, Wright A (2017) The core concept of physiology: A New Paradigm for Teaching Physiology. Springer-Verlag New York DOI: 10.1007/978-14939-6909-8.

Nass R, Hall DH, Miller DM, Blakely RD (2001) Neurotoxin induced degeneration of dopamine neurons in Caenorhabditis elegans. Proceedings of the National Academy of Sciences of the United States of America 99: 3264-3269.

National Research Council U.S. (1993) Committee on Pesticides in the Diets of Infants and Children Pesticides in the diets of infants and Children. National Academy Press, Washington D.C.

Organophosphate pesticides and child health (2007) Department of Environmental \& Occupational Health Sciences, University of Washington.

Palop JJ, Mucke L (2010) Amyloid - $\beta$ Induced Neuronal Dysfunction in Alzheimer's disease: from synapses toward neural networks. Nat Neurosciences 13: 812-818.

Pesticides (2008) Children's Health and the Environment July, WHO Training Package for the Health sector available at www.who.int/ceh access on 28th April 2021.

Rahman AA, Shetty AK, Mohamed B (2001) Subchronic dermal application of N,N- Diethyl m- Tolumide (DEET) and Permethrin to adult rats, alone or in combination, causes diffuse neuronal cell death and cytoskeletal abnormalities in the cerebral cortex and the hippocampus and purkinje neuron loss in the cerebellum. Experimental neurology 172:153-171. 
Ritz BR, Paul KC, Bronstein J (2016) Of Pesticides and Men: a California Story of Genes and Environment in Parkinson's Disease. Current Environmental Health Reports 3(1) DOI:10.1007/s40572-016-0083-2.

The United States Environment Protection Agency (2007) Revised N-Methyl carbamate cumulative risk assessment. Office of Pesticide Programs. Washington DC.

Uversky NV (2004) Neurotoxicant induced animal models of Parkinson's disease: understanding the role of rotenone, Maneb and Paraquat in neurodegeneration. Cell Tissue Research 318:225241 .

Wolozin B, Gabel C, Ferree A, Gwilllily M, Ebata A (2011) Watching worm whither: Modeling neuron degeneration in C.elegans. Progress in Molecular Biology and Translational Science 100:499-514. DOI: https://doi.org/10.1016/B978-0-12 384878-9.00015-7.
World Health Organization (WHO) (1990) Public health impact of pesticides used in agriculture Pp. 1-129.

Yadav SS, Singh MK, Yadav RS (2016) Organophosphates induced Alzheimer's disease: An epigenetic Aspect. Journal of Clinical Epigenetic. 2:1. DOI: 10.21767/2472-1158.100010.

Yu B, Pamphlett R (2017). Environmental insults: critical triggers for amyotrophic lateral sclerosis. Translational Neurodegeneration $6: 15$.

Zhou S, Wang Z, Klaunig JE (2013) Caenorhabditis elegans neuron degeneration and mitochondrial suppression caused by selected environmental chemicals. International Journal of. Biochemistry and Molecular Biology 4: 191-200.

Zuccato C, Valenza M, Cattaneo E (2010) Molecular Mechanisms and Potential Therapeutical Targets in Huntington's disease. Physiological Reviews 90: 905-981. 